\title{
REFLETINDO SOBRE A CONSTRUÇÃO DE IDENTIDADES DIASPÓRICAS: estudo de caso sobre a "hinduidade"
}

\author{
Mirian Santos Ribeiro de Oliveira*
}

\section{Resumo}

Em se tratando da construção de identidades culturais no contexto de intensificação e diversificação de fluxos migratórios característico dos processos de globalização contemporâneos, deve-se destacar a complexidade associada à coexistência de tendências à homogeneidade e à heterogeneidade, bem como à possibilidade de que tais identidades sejam construídas a partir da sociedade de origem ou da sociedade de destino. Por meio da apresentação de um estudo de caso sobre a identidade diaspórica hindu (Hindutva, "hinduidade”), pretende-se analisar a construção de representações sobre a migração de indianos por organizações nacionalistas hindus contemporâneas, concedendo-se especial atenção a dois aspectos de tal construção: (1) a relação entre as dimensões nacional e transnacional em uma concepção de identidade diaspórica elaborada a partir da sociedade de origem; (2) a definição de uma identidade diaspórica em termos religiosos.

Palavras-chave: Diásporas. Identidades culturais. Mobilidade migratória. Índia. Nacionalismo hindu contemporâneo.

Nas últimas décadas do século XX, observou-se a formação de redes de interdependência cada vez mais extensas e complexas, possibilitada pela ocorrência de transformações socioeconômicas fundamentais relacionadas à intensificação dos processos de globalização tais como: a crescente mobilidade do capital e do trabalho, estreitamente vinculada à produção flexível pós-fordista e à interdependência entre economia formal e informal; o desenvolvimento dos meios de comunicação e de transporte e o decorrente incremento da velocidade e da simultaneidade, ocasionando o "encolhimento do mundo" e oferecendo aos atores novos recursos para a construção e manutenção de redes de relações sociais transnacionais (de caráter econômico, religioso, político etc.); a relativização da

\footnotetext{
* Doutoranda em Sociologia pela Universidade São Paulo. E-mail: mirian.ribeiro@usp.br
} 
soberania estatal, evidenciada, por exemplo, pelo número crescente de problemas globais e pela redução da capacidade de controle, pelos Estados, de fluxos de variadas naturezas migratórios, de capitais, de bens etc. (CASTELLS, 1999; COHEN, 1997; FEATHERSTONE, 1996; GEERTZ, 2000; GILROY, 1997; GIDDENS, 2000; HALL, 2003a, 2003b; HOBSBAWM, 1990; MÉDAM, 1993; PERALVA, 2008; SCHNAPPER, 2001; WOODWARD, 1997).

Os processos mencionados apontam na direção de uma crescente dissociação entre práticas econômicas, investimentos identitários e organização política nos moldes do Estadonação. Do ponto de vista cultural, isto significa um aumento da quantidade de grupos sociais que definem suas identidades coletivas por meio de noções de pertença infranacionais ou supranacionais. Deve-se lembrar que o que se observa na fase contemporânea dos processos de globalização é a intensificação da dissociação referida, uma vez que a existência de lealdades e de noções de pertença que vinculam os indivíduos a unidades socioculturais mais abrangentes que os Estados-nação modernos não é um fenômeno recente. As diásporas constituem um dos exemplos importantes desse fato. Além disso, pode-se perceber, no período em questão, uma alteração no valor atribuído a noções de pertença transnacionais, de modo geral, e a noções de pertença construídas e mantidas por grupos diaspóricos, de modo específico (MÉDAM, 1993; SCHNAPPER, 2001). Para os fins deste trabalho, estabelece-se a distinção entre uma percepção pessimista e uma percepção otimista sobre as diásporas. Tais percepções referem-se a um contexto intelectual em que figuram estudos acadêmicos e debates públicos (assim como a formulação de políticas públicas) ligados ao tema da mobilidade migratória.

A percepção pessimista sobre as diásporas remete ao período de formação e consolidação dos Estados-nação modernos e aos processos de construção de identidades nacionais correspondentes. Uma vez que, para o discurso nacionalista, o pertencimento à categoria da nação é anterior a quaisquer outras formas de relações sociais, assim como o indivíduo relaciona-se direta e imediatamente com a nação, houve o desencorajamento da noção de múltiplo pertencimento e a tendência a um universalismo homogeneizador (CALHOUN, 1995). Neste contexto, em que os fluxos migratórios eram ativamente controlados pelos Estados e a temática da integração/assimilação era a tônica do debate sobre mobilidade migratória, grupos com lealdades transnacionais eram considerados passíveis de suspeição e pareciam indicar os limites da integração dos migrantes às sociedades de destino (PERALVA, 2008). Por esta perspectiva, as diásporas foram percebidas como fonte de 
anomia, visto que questionavam a fidelidade à nação e criavam espaços sociais que escapavam ao controle estatal (SCHNAPPER, 2001).

A partir da segunda metade do século XX, paralelamente à intensificação dos processos de globalização, constrói-se uma percepção otimista sobre as diásporas. Visto que a mobilidade se torna um elemento central nas sociedades contemporâneas e que, em decorrência disso, processos transnacionais adquirem cada vez mais relevância, confere-se nova legitimidade a noções de pertença transnacionais existentes anteriormente, como é o caso das identidades diaspóricas. Uma vez que as migrações adquirem um caráter crescentemente transnacional e que, portanto, os fluxos migratórios se autonomizam em relação às sociedades de origem e de destino, observa-se, por um lado, que os debates sobre integração/assimilação dos migrantes perdem importância e, por outro lado, que a multiplicidade de referências e de valores característica das diásporas - associada na maioria das vezes a flexibilidade e hibridez - passa a ser considerada positiva (PERALVA, 2008; SCHNAPPER, 2001).

É possível perceber, ainda, no mesmo período, que a utilização do termo diáspora é mais frequente, ampla e flexível. Antes empregado para designar grupos sociais que, apesar de geograficamente dispersos através de Estados diferentes, mantinham vínculos (materiais e simbólicos) entre si e com suas sociedades de origem - como grupos de judeus, armênios, gregos e chineses que migraram devido a perseguições políticas ou a empreendimentos comerciais -, o vocábulo atualmente se refere a todas as formas de dispersão de populações humanas (SCHNAPPER, 2001). Tal flexibilização do termo pode ser notada tanto no que se refere a pesquisadores de temas relativos a diásporas, como no que diz respeito a membros de grupos diaspóricos.

Em meio à proliferação de conceitos e de autodefinições de diáspora, optou-se, neste trabalho, por adotar uma autodefinição - “diáspora hindu” ou “mundo hindu”, presente do discurso nacionalista hindu contemporâneo - como ponto de partida para a análise da construção de identidades culturais na fase contemporânea dos processos de globalização. Nas seções seguintes serão destacados e problematizados dois aspectos da presença de um discurso sobre a diáspora em um discurso nacionalista: a relação entre a dimensão nacional e a transnacional em uma concepção de identidade diaspórica elaborada a partir da sociedade de origem; a definição de uma identidade diaspórica em termos religiosos. 


\section{Processos de construção de identidades diaspóricas}

Tendo em vista que os processos de globalização contemporâneos não têm caráter uniforme, é possível identificar duas tendências distintas no que se refere à construção de identidades culturais: a) homogeneidade, considerada a tendência cultural dominante, por vezes descrita como um predomínio da cultura estadunidense sobre as demais, ou uma possibilidade de construção de uma identidade global, ou, ainda, a criação de novas variantes de cosmopolitismo; b) heterogeneidade, a disseminação da diferença cultural, que pode assumir um caráter negativo ou positivo. O caráter negativo da construção da diferença está relacionado ao reforço de identidades locais ou particularistas, como no caso de identidades nacionais, étnicas, formas de fundamentalismo religioso, racismo e sexismo, por exemplo. $\mathrm{O}$ caráter positivo da construção da diferença remete, por sua vez, ao hibridismo cultural, à crioulização, ao sincretismo (CASTELLS, 1999; COHEN, 1997; FEATHERSTONE, 1996; GEERTZ, 2000; GIDDENS, 2000; GILROY, 1997; HALL, 2003a, 2003b; HOBSBAWM, 1990; WOODWARD, 1997).

Trata-se, portanto, de um contexto em que são múltiplas as possibilidades de representação de noções de pertença. São igualmente múltiplas as possibilidades de articulação entre as dimensões local/nacional e global/transnacional estabelecidas pelos processos de construção de identidades culturais, como evidencia a construção de uma identidade diaspórica hindu pelo movimento nacionalista hindu contemporâneo. As principais organizações nacionalistas hindus são o Corpo Nacional de Voluntários (Rashtriya Swayamsevak Sangh, RSS), o Partido do Povo Indiano (Bharatiya Janata Party, BJP) e o Conselho Mundial Hindu (Vishwa Hindu Parishad, VHP). Embora, de modo geral, descrições desses grupos enfatizem a integração e a complementaridade das suas áreas de atuação, é importante mencionar a existência de divisões no interior de cada organização, bem como entre elas, no que se refere a considerações ideológicas, táticas e programáticas. Além do mais, não se pode esquecer que representam grupos sociais e regionais distintos: o BJP e o RSS, dotados de maior sofisticação intelectual, são representantes da classe média hindu; o VHP, por sua vez, tem como partidárias as classes trabalhadoras hindus (de educação vernacular) e a classe média baixa (WIRSING e MUKHERJEE, 1995). A despeito de tais diferenças, em termos discursivos existem entre eles pontos convergentes, os quais constituirão o referencial para a análise deste trabalho. 
Hindutva ("hinduidade”) é a identidade nacional-religiosa construída pelos grupos nacionalistas hindus contemporâneos, os quais se apropriaram de concepções ocidentais sobre a história e a própria identidade e elaboraram noções de homogeneidade e unidade nacional, tendo por referência a religião majoritária, o hinduísmo, ressaltando as diferenças em relação a grupos religiosos minoritários (em particular os muçulmanos) e incitando à intolerância contra tais grupos (OLIVEIRA, 2007). Trata-se de uma identidade essencialista, particularista, fortemente marcada pela construção negativa da diferença. A despeito do caráter acentuadamente nacionalista da "hinduidade", é possível identificar, no interior de seu processo de construção discursiva, uma dimensão transnacional. Hindutva é também, no discurso nacionalista hindu contemporâneo, uma identidade diaspórica.

À primeira vista, tal fato poderia indicar a flexibilização da identidade em questão. De fato, as identidades diaspóricas são geralmente percebidas como construções positivas da diferença, caracterizadas pela hibridez, pela flexibilidade, pela manutenção de vínculos com as origens por pessoas que foram dispersadas de sua terra natal, tornaram-se parte de "culturas híbridas” e foram “obrigadas a renunciar ao sonho ou à ambição de redescobrir qualquer tipo de pureza cultural 'perdida' ou de absolutismo étnico” (HALL, 2003a, p. 89; ver também COHEN, 1997; GILROY, 1997). Deve-se considerar, entretanto, que os fluxos migratórios de habitantes de países em desenvolvimento em direção a países desenvolvidos - seja por meio de redes de migração estabelecidas durante os períodos coloniais, seja por meio da emergência de oportunidades seletivas de migração em países como Canadá, EUA e Austrália (COHEN, 1997) - criaram um novo processo de “minorização” nos países de destino. Isso gerou não apenas a possibilidade de uma reação defensiva por parte de grupos étnicos dominantes, que se sentiram ameaçados pela presença de imigrantes, mas, ainda, a possibilidade de que grupos minoritários recorressem a identidades defensivas em resposta à xenofobia. Pode-se observar, em decorrência disso, a construção de concepções fechadas de identidade diaspórica (HALL, 2003a; 2003b) - marcadas pela construção negativa da diferença, ou seja, pelo estabelecimento de oposições rígidas entre os membros do grupo diaspórico e os outros -, o que permite relativizar a perspectiva otimista sobre as diásporas.

Uma segunda percepção corrente nas análises de processos de construção de identidades diaspóricas é a adoção das sociedades de destino como ponto de referência. Identidades diaspóricas concebidas como construções positivas da diferença aparecem associadas a pessoas inseridas em “culturas híbridas”, em constante negociação “com as novas culturas em que vivem, sem simplesmente serem assimiladas por elas e sem perder completamente suas identidades” (HALL, 2003a, p. 88 - grifo meu), o que lhes conferiria 
maior capacidade de articulação entre o global e o local, o universal e o particular (COHEN, 1997). No que se refere a concepções fechadas ou negativas, como no caso da reidentificação com as culturas de origem em reação à xenofobia, trata-se de uma articulação entre o local e o global, relacionada à (re)construção de vínculos simbólicos com um local, região ou país específico a partir das sociedades de destino. Contudo, deve-se considerar que discursos sobre identidades diaspóricas podem ser elaborados a partir das sociedades de origem e difundidos entre os emigrantes - caso da identidade diaspórica hindu -, o que implica outras possibilidades de articulação entre o local e o global, o nacional e o transnacional.

\section{“Hinduidade": a construção de uma identidade (trans)nacional}

Relativamente à construção de identidades culturais em sociedades pós-coloniais, como a indiana, deve-se atentar para o fato de que a experiência da modernidade é indissociável da presença ocidental e, portanto, de relações de dominação colonial, aqui compreendidas como parte de um processo global de longa duração, ligado à expansão europeia por diferentes regiões do mundo, em diferentes períodos da modernidade ocidental (HALL, 2003b; COHEN, 1997; FEATHERSTONE, 1996; HOBSBAWM, 1990). No colonialismo, o conhecimento sobre as populações dominadas - obtido por meio de processos como recenseamento e mapeamento e apresentado em "textos estéticos, eruditos, econômicos, sociológicos, históricos e filológicos” (SAID, 1990, p. 24) - aparece estritamente associado à administração colonial, à intervenção nos modos de organização das sociedades dominadas. Trata-se do que Said denomina orientalismo: um "sistema de conhecimento" sobre as sociedades colonizadas, um “corpo criado de teoria e prática” que pretendia “filtrá-las” para que fossem compreendidas por olhos ocidentais, bem como para que fossem mais bem governadas pelos colonizadores (SAID, 1990, p. 18).

De acordo com esta perspectiva, a experiência da modernidade, na Índia, teria propiciado não apenas o surgimento de novas identidades - como a identidade nacional -, mas, ainda, novos modos de representar antigas identidades - religiosas, de castas, regionais de base linguística, por exemplo (KAVIRAJ, 1997). Os processos de recenseamento, mapeamento e intervenção social introduzidos pelo governo colonial contribuíram para a alteração da autopercepção de grupos sociais locais, uma vez que classificaram a população indiana de acordo com a afiliação religiosa. Embora os britânicos supusessem que todos os colonos pertenciam a alguma religião específica, que determinaria lealdades e conflitos, os 
indianos, por sua vez, consideravam o pertencimento a uma casta como a base para a autoidentificação ${ }^{1}$. Dessa forma, processos sociais complexos, como tensões sociais, lutas políticas ou diferenças culturais, foram analisados segundo uma perspectiva religiosa, o que pode ser considerado uma estratégia ideológica do governo colonial que favoreceu o estabelecimento de divisões rígidas entre os diferentes grupos sociais (SEARLECHATERJEE, 2000; PANIKKAR, 2000).

As primeiras formulações em torno de uma identidade hindu ${ }^{2}$ - presentes em movimentos como a Hindu Mahasabha ${ }^{3}$ (Grande Assembleia Hindu), que procurava criar uma comunidade política hindu e definir a nação indiana por meio de símbolos extraídos exclusivamente de textos, crenças e práticas hindus - ocorreram a partir do final do século 19, principalmente como reação à concessão, por parte da administração colonial britânica, de benefícios especiais a grupos sociais considerados “atrasados” ou desfavorecidos, como os muçulmanos $^{4}$. O tratamento diferencial dispensado pelo governo colonial a grupos considerados minoritários foi concebido como parte de uma estratégia política de “dividir para governar”, com o objetivo de abalar a posição econômica e a unidade emergente dos membros das classes médias educadas, principais representantes do nascente movimento nacionalista indiano (BRASS, 2001; DIXIT, 1986).

Desde então, questões envolvendo as relações entre maiorias e minorias no interior da sociedade indiana - e a autorrepresentação de grupos como majoritários ou minoritários tornaram-se centrais às disputas políticas e aos processos de construção/afirmação de identidades culturais (religiosas, linguísticas, de castas e tribais). O processo de construção de uma identidade hindu por grupos nacionalistas hindus contemporâneos insere-se num contexto de disputa por recursos - cuja distribuição é, em grande medida, determinada pelo processo político - entre a maioria hindu e as minorias religiosas - principalmente os muçulmanos -, bem como entre grupos hindus de castas altas e minorias de castas atrasadas (backward castes) e de castas registradas (dalits ou scheduled castes) (WEINER, 1997; BRASS, 2001). Deve-se ressaltar, entretanto, que a possibilidade de formulação de demandas políticas associadas a identidades definidas em termos religiosos remete a uma das contradições entre a retórica do discurso público indiano e a realidade da prática política. Remete ao fato de que, a despeito da predominância da ideologia secular do Congresso Nacional Indiano após a independência, foram estabelecidas distinções oficiais entre a população hindu e as populações não-hindus do país - como no caso da aprovação do Hindu Code Act, em 1955-6, que estabeleceu um código civil uniforme para todos os hindus do país 
(incluindo membros de outras religiões de origem indiana, como os siques), deixando aos muçulmanos um sistema próprio de Direito Pessoal (BRASS, 2001).

Um aspecto a ser destacado são as implicações da predominância da perspectiva nacional-secular ${ }^{5}$, no período imediatamente posterior à independência, para a construção da identidade nacional-religiosa hindu. Deve-se considerar, em primeiro lugar, que a experiência da Partição ${ }^{6}$, determinante para a adoção de uma constituição secular, significava, em última instância, que demandas políticas baseadas em religião não seriam mais toleradas na Índia independente e que grupos políticos de orientação religiosa seriam pouco influentes na política nacional por algumas décadas. Em segundo lugar, em decorrência do assassinato de Gandhi por Nathuram Godse, um nacionalista hindu, o Corpo Nacional de Voluntários e a Grande Assembleia Hindu - organizações das quais Godse havia sido membro - foram proibidos de atuar durante o período de 1948 a 1949. Trata-se, dessa forma, de um cenário desfavorável à atuação do nacionalismo hindu no interior das instituições políticas indianas (BHATT e MUKTA, 2000; BRASS, 2001; KAVIRAJ, 1997).

É interessante observar que foi nesse cenário - caracterizado pela menor visibilidade do nacionalismo hindu na arena política indiana - que as organizações nacionalistas hindus reformularam o discurso sobre a nação hindu, expandiram-se pela Índia e pelo exterior e elaboraram um discurso sobre a diáspora hindu. Deve-se destacar a importância do Rashtriya Swayamsevak Sangh (Corpo Nacional de Voluntários, RSS) - principal organização nacionalista hindu contemporânea, fundada em 1924 - e de seu líder, Madhav Golwalkar, nesse processo. Golwalkar apresentou uma nova interpretação sobre um dos principais objetivos do nacionalismo hindu - a transformação do Estado indiano em um Estado hindu ao defender a "hinduização" da sociedade indiana. O ideólogo nacionalista hindu aspirava a moldar a sociedade tendo por referência um novo modelo (hindu), de modo que a diferença entre Estado (hindu) e sociedade (hindu) desaparecesse completamente. Para tanto, Golwalkar desenvolveu novas técnicas para colocar em prática a ideologia do nacionalismo hindu no nível da sociedade (e não do Estado): a formação e a organização de homens treinados em shakhas (ramificações) ${ }^{7}$, os swayamsevaks (voluntários), com vistas a difundir e reforçar samskars (visões de mundo) como devoção pela terra materna, sentimento de fraternidade, reverência profunda pelos ideais da nação, disciplina, heroísmo e virilidade (Dixit, 1986). Os shakhas foram importantes não apenas para a difusão da ideologia nacionalista hindu no interior da sociedade indiana mas, também, para a construção da identidade nacional-religiosa hindu entre os emigrantes. 
Após o fim do período em que esteve proibido de atuar, o RSS criou várias outras organizações, entre as quais se encontram o Vishva Hindu Parishad (Conselho Mundial Hindu, VHP), fundado em 1964, e o partido político Jana Sangh, criado em 1951, precursor do atual Bharatiya Janata Party (Partido do Povo Indiano - BJP), formado em 1980. As primeiras organizações nacionalistas hindus no exterior foram ramificações do RSS em países da África Oriental. O próprio RSS, quando narra sua história na diáspora, afirma que seu primeiro shakha fora da Índia foi formado em 1946, a bordo de um navio que levava trabalhadores, mercadores e visitantes que se dirigiam ao Quênia (BHATT, 2000; BHATT e MUKTA, 2000). Essa autodescrição permite associar a presença de grupos nacionalistas hindus no exterior a redes de migração/fluxos migratórios estabelecidos ainda no período colonial britânico e que constituem diásporas de trabalho e diásporas mercantis - a expansão, a partir da terra natal, em busca de trabalho e de comércio, respectivamente (COHEN, 1997).

Quando têm por referência apenas as relações verticais entre colonizadores e colonizados, é provável que as análises sobre processos de construção de identidades diaspóricas se concentrem nos fluxos migratórios das colônias (ou ex-colônias) em direção às metrópoles e na reconfiguração de relações de poder e subordinação na sociedade de destino como no caso da presença dos “filhos do Império” em solo britânico (HALL, 2003b). Entretanto, se se adota a perspectiva de que a colonização é parte de um processo global de longa duração que envolve também "ligações transversais ou que cruzam as fronteiras dos Estados-nação” (HALL, 2003b, p. 113), observam-se fluxos migratórios de outra natureza no interior das próprias colônias - migrações internas de funcionários públicos indianos (VAN DER VEER, 1995) - ou envolvendo diferentes colônias - caso dos contratos de aprendizagem (indenture) por meio dos quais, no período de 1830 a 1920, indianos foram levados, sob condições extremas de exploração, para várias plantações tropicais britânicas, holandesas e francesas em Fiji, Sri Lanka, Suriname, Guiana, Ilhas Maurício, Malásia, Trinidad e África do Sul (COHEN, 1997; LAL, 1997a, 1997b). Neste sentido, é importante observar, no que se refere às redes de migração estabelecidas durante o período colonial, que a emigração para a metrópole constitui uma entre as diferentes possibilidades existentes. A criação das primeiras filiais de organizações nacionalistas hindus no exterior, nas décadas de 1950 e 1960, insere-se em fluxos migratórios originados ainda no período colonial e mantidos no período posterior à independência - a emigração de comerciantes indianos para a África Oriental nas primeiras décadas do século XX -, assim como fluxos migratórios entre a Índia e o Reino Unido. A experiência na África Oriental pode ser considerada a primeira etapa de uma dupla jornada de emigração (da Índia para a África e desta para o Reino Unido). 
A experiência na África Oriental, especialmente no Quênia - retratada como uma “época dourada”, um período de formação no qual antigos ativistas nacionalistas hindus, agora residentes no Reino Unido, frequentaram shakhas e receberam pela primeira vez seus samskars (visões de mundo) -, permitiu a recriação de um “ambiente de tradição” hindu radicalmente diferente, que se tornou um espaço para a construção de projetos políticoreligiosos por castas hindus hegemônicas (BHATT, 2000). Pode-se dizer que a presença na África forneceu o ambiente adequado para o fortalecimento da construção de uma identidade hindu homogênea, uma vez que os treinamentos intensivos recebidos e a transmissão de visões de mundo de Hindutva ocorreram em um país estrangeiro, o que amenizou as contestações acerca da identidade indiana - existentes principalmente na Índia (LAL, 1997a, 1997b) - e favoreceu a construção de uma identidade exclusivamente hindu, com pretensões à representação dos indianos como um todo, o que, em última instância, fortaleceu o caráter nacional da identidade em questão.

Além do mais, deve-se destacar a presença de grupos missionários hindus nos fluxos migratórios originados desde o período colonial. No século 19, missionários da Arya Samaj (Sociedade Ariana) - organização reformista fundada em 1875 por Dayanand Saraswati ${ }^{8}$-, foram enviados a áreas onde havia indianos trabalhando sob o regime de contratos de aprendizagem. Mais tarde, com a intensificação dos movimentos migratórios em direção ao Ocidente, foram fundadas instituições educacionais da Sociedade Ariana em várias partes do mundo, as quais estimularam o contato de outras gerações com os eventos ocorridos na Índia (VAN DER VEER, 1995, 2001; BHATT e MUKTA, 2000). A presença de grupos como a Arya Samaj, além de Sai Baba e Hare Krishna, em regiões com número significativo de imigrantes indianos, aponta para a tendência de manutenção da ligação religiosa com a “Grande Tradição”, mesmo onde a autoridade dos brâmanes era contestada, por meio de missões religiosas vindas da Índia - e não pela formação de novas lideranças ou movimentos religiosos de inspiração hindu nas sociedades de destino (COHEN, 1997).

Tendo-se por referência o RSS - que, por meio das atividades dos shakhas, procurou criar ambientes de tradição hindu nas sociedades de destino, enfatizando a formação de indivíduos diretamente envolvidos com a causa do nacionalismo hindu contemporâneo -, o modo de atuação do Conselho Mundial Hindu (VHP) representa uma ampliação do alcance do discurso nacionalista hindu contemporâneo, uma vez que dialoga com o ambiente de tradição dos emigrantes indianos, (re)criado por missões religiosas e outras organizações, inclusive o RSS. Devido à maior flexibilidade de sua estrutura organizacional - não é constituído por centros de treinamento, caso dos shakhas do RSS, mas suas atividades 
abrangem conferências mundiais, palestras, educação, publicação de livros, recepção de sadhus $^{9}$ que excursionam pelo Ocidente, etc. - e à utilização da estratégia de apelo ao que é familiar - apelo que se dirige especialmente aos devotos e, assim, mobiliza as massas de imigrantes hindus -, o Conselho consegue fazer com que a noção de "hinduidade” atinja não apenas os imigrantes hindus de classe média, principais apoiadores de Hindutva no exterior, mas, ainda, devotos hindus de classes baixas, que não são defensores declarados do nacionalismo hindu (MUKTA, 2000a).

Por fim, pode-se perceber que, diante da mencionada expansão de organizações nacionalistas hindus para o exterior e do aumento da visibilidade de parte dos emigrantes indianos, as organizações nacionalistas hindus, na Índia, rearticularam-se discursivamente, de modo a incorporar os emigrantes às narrativas sobre a nação hindu. Do ponto de vista religioso, as restrições impostas à emigração - algumas tradições do Norte da Índia consideravam o território indiano sagrado e, em decorrência disso, limitavam a importância simbólica dos emigrantes e, de modo geral, no período anterior à independência, os hindus que deixassem a Índia não mais pertenceriam a uma casta, estando sujeitos a sanções - foram gradativamente abandonadas a partir do período colonial britânico e principalmente após a independência devido a reformulações de crenças e práticas religiosas realizadas por movimentos reformistas hindus. As reinterpretações das regras de pertencimento à religião hindu, levadas a cabo nesse período, influenciaram significativamente Golwalkar ${ }^{10}$, o qual, ao discorrer sobre a identidade nacional hindu em sua obra Bunch of Thoughts, de 1966, referiase à missão mundial hindu de salvar a humanidade de seu atual estado de degradação. A missão foi identificada com a ideologia de Hindutva e os agentes da missão, com os hindus vivendo no exterior, principalmente com aqueles organizados sob a égide dos grupos nacionalistas hindus - os swayamsevaks, voluntários da nação hindu -, considerados por Golwalkar os únicos capazes de “iluminar a humanidade” (BHATT, 2000). No que se refere ao discurso do Conselho Mundial Hindu sobre os emigrantes, observa-se que a definição de hindu - para o VHP, hindus seriam todas as pessoas que seguem, respeitam ou acreditam nos “valores eternos da vida” que floresceram na Índia, não importa que ali tenham nascido ou que vivam fora do país - permite fortalecer o sentimento de pertencimento dos emigrantes indianos à diáspora hindu - o “mundo hindu”, compreendido pelo Conselho como uma "vasta sociedade hindu vivendo nesta terra [a Índia] e dispersa pelo globo em pequenas e grandes quantidades”.

Deve-se ressaltar que a construção discursiva de um “mundo hindu” - ou diáspora hindu - se insere num processo de reconstrução da percepção sobre os emigrantes que remete 
à passagem de uma perspectiva pessimista a uma perspectiva otimista sobre as diásporas. Os emigrantes, antes percebidos como uma escória, passam a ser retratados como os emissários da sociedades de origem no cenário internacional. Do ponto de vista das sociedades de origem, exportadoras de mão-de-obra, essa alteração na percepção sobre os emigrantes está associada em grande medida ao crescimento do volume das remessas de divisas que recebem dos migrantes, assim como ao aumento da importância que se atribui à relação entre tais remessas e o desenvolvimento (MÉDAM, 1993; PERALVA, 2008; SCHNAPPER, 2001). No caso da Índia, mais especificamente, pode-se observar que, ao longo da segunda metade do século $\mathrm{XX}$, quando se intensificaram os fluxos migratórios originários do país, houve um crescimento significativo do volume de remessas de divisas de emigrantes indianos para a sociedade de origem. Estima-se que, em 2008, a Índia tenha recebido cerca de 52 bilhões de dólares em remessas de divisas, o que a torna a maior receptora de remessas entre os países em desenvolvimento, seguida pela China (40,6 bilhões de dólares) e o México (26,3 bilhões de dólares) (RATHA, MOHAPATRA e SILWAL, 2009). Além disso, há estimativas de que, de modo geral, a diáspora indiana seja a sexta maior do mundo, com cerca de 836.780 membros, que se dirigem principalmente aos Estados Unidos. No que se refere a diásporas de mão-obra altamente qualificadas, a indiana é a terceira maior do mundo, com aproximadamente 664.406 membros (BEINE, DOCQUIER E ÖZDEN, 2009).

Em se tratando da imagem dos emigrantes na sociedade de origem, pode-se dizer que o posicionamento do governo indiano e das elites educadas, a princípio, era marcado pela negligência ou pela percepção dos mesmos como um "lembrete de tudo o que a Índia deveria abandonar, se desejasse ser vista como uma nação marchando rumo ao progresso e ao desenvolvimento” (LAL, 2004, p. 4) (tradução minha). Entretanto, diante do aumento da importância econômica de indianos vivendo no exterior, ou de descendentes de indianos, construiu-se uma nova imagem dos emigrantes (BHATT, 2000). ${ }^{11}$ De modo mais específico, a nova percepção em questão remete a uma parcela dos indianos vivendo no exterior especialmente em países desenvolvidos - e destaca seu sucesso econômico (LAL, 2004).

Sobre a diáspora: pensando as inter-relações entre nacionalidade $e$ transnacionalidade

A autodefinição “diáspora hindu” evidencia algumas das complexidades dos processos de construção de identidades culturais na fase contemporânea de globalização, especialmente 
no que se refere à relação entre nacionalismo e transnacionalismo. Compreender o modo pelo qual as dimensões nacional e transnacional se relacionam envolve considerar a construção de identidades culturais, por nacionais e emigrantes, no interior de "ligações transversais ou que cruzam as fronteiras dos Estados-nação" e de "inter-relacionamentos global/local que não podem ser inferidos nos moldes de um Estado-nação” (HALL, 2003b, p. 113). No caso da identidade diaspórica hindu, isso implica analisar a difusão da "hinduidade”, tal como concebida pelos nacionalistas hindus contemporâneos, entre os emigrantes indianos, assim como a forma pela qual as identidades construídas entre os próprios emigrantes se articulam com a ideologia de Hindutva e influenciam as identidades formadas no subcontinente indiano (MUKTA, 2000b). Esta perspectiva aponta na direção de inter-relações complexas de influência entre as dimensões nacional e transnacional e permite questionar, portanto, uma concepção corrente em se tratando de análises sobre identidades diaspóricas: a ideia de que diásporas são antinacionais, a qual estabelece uma relação de oposição entre nacionalismo e transnacionalismo.

A fim de se proceder a essa discussão, apresenta-se a definição de diáspora de Paul Gilroy, bastante representativa da perspectiva (acadêmica) otimista sobre as diásporas. Para o autor, diáspora é uma rede relacional produzida pelo deslocamento involuntário de grupos humanos, cujos fatores de expulsão são guerra, fome, escravidão, limpeza étnica, conquista e repressão política. Tais grupos mantêm ligações com a terra de origem por meio da recordação e do sentimento forte de que há perigos envolvidos no esquecimento do local de origem e do processo de dispersão. Segundo o autor, trata-se de um conceito extra-nacional, o que implica a análise de formas e processos interculturais e transculturais - ou seja, de relações de pertencimento mais amplas ou mais restritas do que as concebidas quando se tem por referência o Estado-nação -, assim como aponta para a relação ambivalente entre diáspora e nacionalismo. Por um lado, o Estado-nação pode ser considerado um modo de eliminar a dispersão - seja por meio da assimilação dos imigrantes à sociedade de destino, seja por meio do retorno à sociedade de origem. Por outro lado, o autor considera o conceito de diáspora explicitamente antinacional. A identidade diaspórica, antiessencialista - uma vez que enfatiza as noções de espaço, espacialidade, distância, viagem e movimento - contrapõe-se ao caráter essencialista $^{12}$ da identidade nacional - associado às concepções tradicionais das ciências humanas de tempo, temporalidade, fixidez, enraizamento e sedentarismo -, assim como ultrapassa as noções de pertença próprias à cidadania moderna e, por vezes, opõe-se a elas. Nesse sentido, a relação entre nacionalismo e transnacionalismo seria de oposição e até 
mesmo de superação: as identidades diaspóricas não apenas seriam antinacionais como constituiriam uma noção de pertença alternativa às identidades nacionais (GILROY, 1997).

A ideia de oposição entre o nacional e o transnacional - e de superação do nacional pelo transnacional - poderia sugerir que a construção de identidades nacionais é anterior ao surgimento de processos transnacionais e que, dessa forma, identidades transnacionais substituiriam as identidades nacionais. Entretanto, levando-se em consideração o período de formação de comunidades nacionais territorialmente definidas, percebe-se que a construção de identidades nacionais é indissociável de processos de globalização de longa duração e, portanto, de processos transnacionais (CALHOUN, 2001; HALL, 2003b; VAN DER VEER, 1995).

É irônico que tenha sido no final do século XIX, no exato momento em que a globalização da organização política e econômica e os fluxos globais de cultura atingiam níveis sem precedentes que a necessidade de organizar a vida social em termos de fronteiras bem definidas, identidades nacionais e categorias culturais essencialistas atingiu o seu ápice. Na Europa, foi o período em que os nacionalistas começaram efetivamente a pressionar pelo controle da imigração (...) Nenhuma outra era enfatizou mais a autonomia do Estado-nação ou a capacidade de a ideia de nação definir as identidades coletivas em grande escala. E essa ênfase ocorreu exatamente quando o mundo estava se tornando bem mais internacional e, em parte, precisamente por essa razão. Aqui pode estar uma lição, para o momento atual, no qual a aceleração dos processos globais de acumulação de capital, a rápida transferência global de tecnologia, a divulgação quase instantânea dos produtos culturais e as enormes ondas de migração podem induzir algumas pessoas a acreditarem que o Estado-nação está prestes a desaparecer nas sombras da história (CALHOUN, 2001, p. 209-10).

Observa-se, portanto, que identidades nacionais foram construídas em um ambiente transnacional, o qual, no caso indiano, remete à ocupação da Índia pela Companhia das Índias Orientais (East India Company - EIC), de princípios do século 17 a meados do século 18, como uma empresa essencialmente comercial e transnacional. ${ }^{13}$ Além do mais, o período de colonização britânica no subcontinente indiano foi também o período de unificação interna da Grã-Bretanha, o que aponta para o caráter inacabado da construção da nação e para a simultaneidade dos processos na metrópole e na colônia (VAN DER VEER, 2001).

Deve-se considerar, ainda, que o período colonial britânico foi marcado pela simultaneidade de processos de dispersão de grupos humanos a partir da metrópole e da colônia. Em se tratando do conceito de diáspora, as razões de dispersão são muitas vezes eventos traumáticos, mas deve-se ponderar que, mesmo no caso da diáspora judaica - uma diáspora de vítima -, visto que os judeus não são um povo único com uma origem e uma 
história de emigração únicas, o elemento voluntarista da emigração não pode ser desconsiderado. Por isso, devem-se acrescentar ao conceito de diáspora motivos de dispersão relacionados à expansão a partir da terra de origem em busca de trabalho, comércio ou ambições coloniais - os quais caracterizam as diásporas de trabalho, mercantis e imperiais, respectivamente (COHEN, 1997). Os contratos de aprendizagem (indenture) de indianos e a dominação colonial britânica em diversas regiões do mundo, inclusive na Índia, que podem ser apontados como os principais exemplos de diáspora de trabalho e diáspora imperial, propiciaram a reificação de identidades nacionais tanto entre indianos como entre britânicos (COHEN, 1997; VAN DER VEER, 1995).

A análise da identidade nacional-religiosa hindu - que, no período posterior à independência, com a expansão da rede de organizações nacionalistas hindus para o exterior e a formulação de um discurso sobre a diáspora hindu adquire uma dimensão transnacional também permite questionar a relação de oposição entre nacionalismo e transnacionalismo. Pode-se observar, em primeiro lugar, que se trata de uma identidade diaspórica construída a partir da sociedade de origem, na qual coexistem as noções de pertença a um Estado-nação (descrito como a "nação hindu”) e a uma unidade sociocultural mais abrangente que o Estadonação (o “mundo hindu”).

Em segundo lugar, a autoidentificação como diáspora hindu está associada à articulação da "hinduidade" com identidades construídas entre os próprios emigrantes. Em se tratando dos movimentos migratórios originados a partir do Sul da Ásia, os termos “diáspora hindu” ou “comunidades hindus” são historicamente imprecisos e politicamente significativos. Observando-se os fluxos migratórios indianos ${ }^{14}$ ao longo da história, percebese que as motivações para a dispersão foram diversificadas, sendo possível identificar principalmente diásporas de trabalho e mercantis. Entretanto, a possibilidade de encontrar algo especificamente hindu nas ondas de migração indianas é muito reduzida (BHATT, 2000). Tendo-se como referência apenas duas de tais ondas de migração, particularmente importantes para a compreensão do processo de construção da identidade diaspórica por grupos nacionalistas hindus contemporâneos, é possível perceber que, entre os primeiros indianos que se dirigiram ao Quênia, após a década de 1860, havia uma maioria de siques (grupos numericamente significativos de hindus e muçulmanos se estabeleceram no país posteriormente, com o aumento das oportunidades de trabalho); no caso do Reino Unido, os pársis formaram as primeiras comunidades de imigrantes indianos, a partir dos séculos 18 e 19. É neste sentido que se considera imprecisa a utilização do termo diáspora hindu: quando se faz referência aos fluxos migratórios originados a partir da Índia, considera-se a emigração 
de indianos e não exclusivamente de hindus (BHATT, 2000). Tratar-se-ia, portanto, de uma diáspora indiana e não de uma diáspora hindu.

A despeito de não se registrarem ocorrências que tenham causado especificamente a emigração hindu, o tema da dispersão é empregado por grupos nacionalistas hindus contemporâneos por ser politicamente significativo (BHATT, 2000). A apropriação de termos como “diáspora hindu” e a descrição de processos e histórias de migração complexos em termos exclusivamente religiosos estão relacionadas ao objetivo de construir a imagem de uma diáspora especificamente religiosa e hereditária, o que permitiria, por um lado, fortalecer a autoidentificação - conferir aos grupos de emigrantes indianos um caráter de homogeneidade e reforçar o fato de que os indianos vivendo no exterior pertenceriam à "nação hindu" - e, por outro lado, delimitar diferenças entre os emigrantes hindus e os outros - ressaltar a "ferida hindu”.

A “ferida hindu” está associada a um dos temas centrais do discurso nacionalista hindu contemporâneo - a responsabilização da conquista muçulmana e de seu longo governo sobre a Índia pela impossibilidade de emergência do país como uma nação (WARIAVWALLA, 2000) - e, dessa forma, às disputas envolvendo a maioria hindu e a minoria muçulmana no interior da sociedade indiana. Para as organizações nacionalistas hindus contemporâneas, as minorias muçulmanas constituiriam uma ameaça interna aos hindus e, em âmbito internacional, seriam um problema delicado para o Ocidente de modo geral. Duras críticas são dirigidas a políticos indianos que "apaziguariam” as minorias religiosas concedendo-lhes direitos especiais. A maioria hindu seria vitimada, assim, pela negligência e pelo oportunismo de políticos que "ferem" a comunidade religiosa dominante (hindu), ao deixarem de defender seus interesses. No que se refere ao discurso sobre a diáspora, esta é caracterizada pelos próprios nacionalistas hindus como uma diáspora de vítima - são evocados acontecimentos trágicos que teriam levado à dispersão do povo hindu, bem como a memória de uma terra natal perdida ou imaginada que ainda deve ser estabelecida -, apesar da dificuldade de se identificar eventos traumáticos que tenham causado a dispersão de hindus.

Pode-se dizer que se trata de uma concepção fechada de identidade diaspórica, uma vez que enfatiza a diferença entre hindus e todas as outras minorias étnicas no Ocidente (BHATT, 2000). Entre os emigrantes, tal concepção fechada de diáspora, pode ser construída em reação à xenofobia, levando-os à reidentificação com as culturas de origem (Hall, 2003b), o que por vezes ocorre por meio do nacionalismo, como no caso daqueles que, antes da emigração, não pensavam em si mesmos como indianos mas se tornaram indianos na diáspora (VAN DER VEER, 1995). As razões pelas quais os indianos no Reino Unido, por exemplo, 
adotam a denominação "hindu” são múltiplas e complexas, mas estão em grande parte relacionadas a sua condição de minoria, a qual implica duas reivindicações principais: o reconhecimento da existência de um grupo minoritário hindu, que mereceria oportunidades iguais às oferecidas aos britânicos; o abandono da denominação "asiáticos” para se referir aos hindus, o que reflete, entre outras coisas, o desejo dos hindus de se distinguirem dos muçulmanos que vivem no Reino Unido (RAJ, 2000). Tal condição de minoria dos emigrantes hindus, nas sociedades de destino, favoreceria a identificação com a imagem da “ferida hindu" mesmo onde obtiveram êxito econômico, como no caso de grupos de indianos que vivem nos Estados Unidos, uma vez que não gozam do mesmo status que os nacionais e não têm influência política. É importante observar, ainda, que a articulação entre a "hinduidade” e as identidades construídas entre os emigrantes também exerce influência sobre as identidades formadas no subcontinente indiano. Deve-se levar em consideração que os indianos que vivem no exterior constituem um modelo para as classes médias na Índia, o que implica que, além do modo de vida, a forte consciência de minoria dos emigrantes influencia as classes médias indianas, reforçando o discurso de vitimização hindu no interior da sociedade de origem (MUKTA, 2000b). Além do mais, é possível perceber que, nas últimas décadas, as elites indianas, conjuntamente com emigrantes aliados à causa do nacionalismo hindu, adquiriram posições significativas de poder, por meio das quais podem empregar recursos materiais, políticos e culturais para pressionar as autoridades políticas indianas em favor de seus interesses. Ao se retratarem como "feridas", essas elites procuram exercer pressão política no interior do Estado indiano, no que obtêm o apoio de hindus vivendo no exterior (MUKTA, 2000a).

\section{Considerações finais}

Por meio da análise do processo de construção da identidade diaspórica hindu, é possível reconhecer a complexidade e a multiplicidade dos modos de articulação entre o nacional e o transnacional e questionar algumas das concepções correntes nos estudos sobre diásporas. Pode-se dizer que a relação entre as dimensões nacional e transnacional é uma relação de influência mútua, por meio da qual processos transnacionais permitem a criação e o fortalecimento de identidades nacionais, bem como processos nacionais estimulam a criação e o fortalecimento de identidades diaspóricas. 
Reconhece-se aqui a importância da influência da dimensão transnacional sobre a nacional, o que envolve o reconhecimento da importância do estudo de identidades construídas entre os próprios emigrantes, bem como da articulação de tais identidades com discursos nacionalistas na sociedade de origem (COHEN, 1997; HALL, 2003a; MUKTA, 2000b). Entretanto, tendo em vista os questionamentos sobre duas concepções usuais nas investigações sobre identidades diaspóricas - o caráter antinacional das diásporas e a adoção das sociedades de destino como ponto de referência em tais investigações - suscitados pela análise preliminar da noção de "hinduidade”, destaca-se aqui a influência da dimensão nacional sobre a transnacional. De modo mais específico, ressalta-se a importância de práticas e processos locais (nacionais) para a construção da dimensão global (transnacional).

Do ponto de vista da construção de identidades culturais, deve-se atentar para o fato de que a imigração e a etnicidade, ao lado da internacionalização do capital, são aspectos fundamentais do estágio contemporâneo de globalização. Isso porque formam um “conjunto de processos por meio do qual elementos globais são localizados, os mercados de trabalho internacionais são constituídos e culturas do mundo inteiro são desterritorializadas e reterritorializadas” (SASSEN, 2001, tradução minha). Dessa forma, processos locais (regionais/nacionais) não apenas sustentam a circulação de mercadorias, pessoas, fluxos financeiros e de informações em âmbito global (internacional/transnacional), como também propiciam a formação de identidades transnacionais. É nesse sentido que se pode dizer que o nacional constrói o transnacional, tanto do ponto de vista material como do ponto de vista simbólico.

\title{
ON DIASPORIC IDENTITIES CONSTRUCTION: case study on Hinduness
}

\begin{abstract}
The complexity of cultural identities construction - in a context of increasingly intense and diverse migratory flows, characteristic of contemporary globalization processes - is related to the coexistence of trends toward homogeneity and heterogeneity, as well as to the possibility of constructing such identities from the homeland or from the host societies. Through a case study on Hindutva (Hinduness), a Hindu diasporic identity, we intend to look into how contemporary Hindu nationalist organizations represent migration, stressing particularly: (1) the relationship between national and transnational dimensions in a diasporic identity constructed from the homeland; (2) the religious definition of such diasporic identity.
\end{abstract}

Keywords: Diasporas. Cultural identities. Migratory mobility. India. Contemporary hindu nationalism. 


\section{Referências}

BEINE, Michel; Docquier, Frédéric; Özden, Çaglar. Diásporas. Policy Research Working Paper 4984. The World Bank Development Research Group. Trade and Integration Team, July 2009. Disponível em: <http://econ.worldbank.org> Acesso em: 30 jul. 2009.

BHATT, Chetan. Dharmo rakshati rakshitah: Hindutva movements in the UK. Ethnic \& Racial Studies, London, v. 23, n. 3, May 2000. p. 559-593,

BHATT, Chetan; MUKTA, Parita. Hindutva in the West: Mapping the Antinomies of Diaspora Nationalism. Ethnic \& Racial Studies, London, v. 23, n. 3, May 2000. p. 407- 441.

BRASS, Paul. The politics of India since independence. Cambridge: Cambridge University Press, 2001. $2^{\text {nd }}$ edition.

CALHOUN, Craig. Nationalism and difference: the politics of identity writ large. In: CALHOUN, Craig. Critical Social Theory: Culture, History and the Challenge of Difference. Oxford UK \& Cambridge USA: Blackwell, 1995.

CALHOUN, Craig. Multiculturalismo e nacionalismo, ou por que sentir-se em casa não substitui o espaço público. In: MENDES, Candido (org.) Pluralismo cultural, identidade e globalização. Rio de Janeiro: Record, 2001.

CASTELLS, Manuel. Paraísos comunais: identidade e significado na sociedade em rede. In: . O poder da identidade. São Paulo: Paz e Terra, 1999.

COHEN, Robin. Global diasporas. An introduction. London: UCL Press, 1997.

DIXIT, Prabha. The ideology of Hindu nationalism. In: PANTHAM, Thomas; DEUTSCH, Kenneth L. (Eds.) Political thought in modern India. New Delhi: Sage Publications, 1986.

ELIAS, Norbert; SCOTSON, J. L. Os estabelecidos e os outsiders: sociologia das relações de poder a partir de uma pequena comunidade. Rio de Janeiro: Jorge Zahar Ed., 2000.

FEATHERSTONE, M. O desmanche da cultura. São Paulo: Studio Nobel, 1996.

GEERTZ, Clifford. O mundo em pedaços: cultura e política no fim do século. In: GEERTZ, Clifford. Nova luz sobre a antropologia. Rio de Janeiro: Jorge Zahar Editor, 2000.

GIDDENS, Anthony. Globalização. In: Mundo em descontrole. São Paulo: Record, 2000.

GILROY, Paul. Diaspora and the detours of identity. In: WOODWARD, Kathryn (Ed.). Identity and difference. Sage Publications: London, Thousand Oaks, New Delhi, 1997.

GOLWALKAR, M.S. Bunch of thoughts. Bangalore: Sahitya Sindhu Prakashan, 1996.

HALL, Stuart. A identidade cultural na pós-modernidade. Rio de Janeiro: DP\&A, 2003a.

HALL, Stuart. Da diáspora. Identidades e mediações culturais. Organização Liv Sovik. Belo Horizonte: Editora UFMG; Brasília: Representação da UNESCO no Brasil, 2003b. 
HIGH LEVEL COMITEE ON THE INDIAN DIASPORA. Report of the High Level Comitee on the Indian Diaspora. New Delhi, Jan. 2002. Disponível em: <http://indiandiaspora.nic.in/> Acesso em: 30 out. 2006.

HOBSBAWM, Eric. Nações e nacionalismo desde 1780: programa, mito e realidade. Rio de Janeiro: Paz e Terra, 1990.

KAVIRAJ, Sudipta (Ed.). Politics in India. New Delhi: Oxford University Press, 1997.

LAL, Vinay. Reflections on the Indian diaspora. 1997a. Disponível em:

<http://www.sscnet.ucla.edu/southasia/Diaspora/diaspora.html> Acesso em: 10 abr. 2004.

LAL, Vinay. The Indian diaspora. 1997b. Disponível em:

<http://www.sscnet.ucla.edu/southasia/Diaspora/diaspora.html> Acesso em: 10 abr. 2004.

LAL, Vinay. Labour and longing. Seminar, n. 538, June 2004. Disponível em: <www.indiaseminar.com> Acesso em: 7 nov. 2006.

MADHOK, B.; RAO, K. S. N.; SESHADRI, H. V.; SUDARSHAN, K. S. Why Hindu Rashtra? Delhi: Suruchi Prakashan, 1990. Disponível em:

http://www.hindubooks.org/whr/index.htm. Acesso em: 28 jul. 2003.

MÉDAM, Alain. Diaspora/Diasporas. Archétype et typologie. Revue Européenne de Migrations Internationales, v. 9, n.1, 1993. p. 59-66. Disponível em: <http://www.persee.fr> Acesso em: 29 jun. 2009.

MUKTA, Parita. The public face of Hindu nationalism. Ethnic \& Racial Studies, London, v. 23, n. 3, May 2000a. p. 442-466.

MUKTA, Parita. Romila Thapar: On historical scholarship and the uses of the past (interview with Parita Mukta). Ethnic \& Racial Studies, London, v. 23, n. 3, May 2000b. p. 594-616.

OFFICE OF THE REGISTRAR GENERAL \& CENSUS COMISSIONER. Census of India. New Delhi, 2001. Disponível em: <www.censusindia.gov.in> Acesso em: 25 mar. 2007.

OLIVEIRA, Mirian S. R. de. $O$ "mundo hindu”: identidade nacional e intolerância religiosa no discurso nacionalista hindu contemporâneo. 2007.Dissertação (Mestrado em Sociologia). Belo Horizonte, FAFICH/UFMG.

PANIKKAR, K. M. A survey of Indian History. Bombay: Asia Publishing House, 1964. . A dominação ocidental na Ásia. Do século XV aos nossos dias. Rio de Janeiro: Paz e Terra, 1977.

. Outsider as enemy: the politics of rewriting history in India. Columbia International Affairs Online, Columbia, November 2000. Disponível em:

<http://www.ciaonet.org/frame/wpsfrm.html> Acesso em: 9 abr. 2003.

PERALVA, Angelina. Globalização, migrações transnacionais e identidades nacionais. Coesão Social na América Latina: bases para uma nova agenda democrática. São Paulo: 
Instituto Fernando Henrique Cardoso, 2008. Disponível em:

<http://www.plataformademocratica.org> Acesso em: 31 jan. 2009.

POUCHEPADASS, Jacques. Índia: o primeiro século colonial. In: FERRO, Marc (Org.). O livro negro do colonialismo. Rio de Janeiro: Ediouro, 2004.

RAJ, Dhooleka Sarhadi. 'Who the hell do you think you are?' Promoting religious identity among young Hindus in Britain. Ethnic \& Racial Studies, London, v. 23, n. 3, May 2000. p. 535-558.

RATHA, Dilip; MOHAPATRA, Sanka; SILWAL, Ani. Migration and Development Brief 10. Development Prospects Group, World Bank. Migration and Remittances Team. July 13, 2009. Disponível em: <http://econ.worldbank.org> Acesso em: 30 jul. 2009.

SAID, Edward W. Orientalismo. O Oriente como invenção do Ocidente. São Paulo: Companhia das Letras, 1990.

SASSEN, Saskia. The global city: strategic site/new frontier. Seminar, n. 503, July 2001. Disponível em: <www.india-seminar.com> Acesso em: 9 mai. 2009.

SAVARKAR, V.D. Hindutva: who is a Hindu? $6^{\text {th }}$ edn. Bombay: Veer Savarkar Prakashan, 1989.

SCHNAPPER, Dominique. De l'État-nation au monde transnational. Du sens et de l'utilité du concept de diaspora. Revue Européenne de Migrations Internationales, v. 17, n.2, 2001. p. 9-36. Disponível em: <http://www.persee.fr> Acesso em: 28 jun. 2009.

SEARLE-CHATTERJEE, Mary. 'World religions' and 'ethnic groups': do these paradigms lend themselves to the cause of Hindu nationalism? Ethnic \& Racial Studies, London, v. 23, n. 3, May 2000. p. 497-515.

THAPAR, Romila. Historia de la India. [S.l.] Fondo de Cultura Económica, 1969, v. 2.

VEER, Peter van der. Imperial Encounters. Religion and modernity in India and Britain. Princeton: Princeton University Press, 2001.

VEER, Peter van der (Ed.). Nation and migration. The politics of space in the South Asian Diaspora. Philadelphia: University of Pennsylvania Press, 1995.

VEER, Peter van der. Religion in South Asia. Annual Review of Anthropology, [S.l.], v. 31, n. 1. May 2002. p. 173-187.

WARIAVWALLA, Bharat. Religion and Nationalism in India. Ram The God of the Hindu Nation. Round Table, London, v. 357, Oct. 2000. p. 593-605.

WEINER, Myron. Minority identities. In: KAVIRAJ, Sudipta (Ed.). Politics in India. New Delhi: Oxford University Press, 1997. 
WIRSING, R. G.; MUKHERJEE, D. The saffron surge in Indian Politics: Hindu nationalism and the future of secularism. Asian Affairs: An American Review, Washington D.C., v. 22, n. 3, Fall 1995. p. 181- 206.

WOODWARD, Kathryn (Ed.). Identity and difference. Sage Publications: London, Thousand Oaks, New Delhi, 1997.

\begin{abstract}
${ }^{1}$ É importante mencionar que, embora o sistema de castas tenha sido justificado por crenças e práticas religiosas, não pode ser compreendido apenas em termos religiosos. Tal sistema foi construído por "uma política sistemática de fechamento e exclusão por parte do grupo estabelecido em seu relacionamento com a população dominada (...) [À] medida que a sociedade hindu tornou-se mais diferenciada, foi assumindo o caráter de uma hierarquia de castas hereditárias (...) Assim como, nos primeiros tempos, as populações não arianas subjugadas foram rigidamente excluídas da participação nos rituais e orações dos grupos dominantes, também todas as divisões funcionais da sociedade indiana, posteriormente, desde os sacerdotes até os varredores de rua, foram concebidas em termos de uma exclusão sancionada pela religião, de uma hierarquia de divisões sociais hereditárias entre castas superiores e inferiores” (ELIAS e SCOTSON, 2000, p. 47-8).
\end{abstract}

${ }^{2}$ Faz-se necessário distinguir os termos hindu e indiano. Hindu refere-se ao seguidor de diversos segmentos de uma religião indiana específica, o hinduísmo. Indiano, por sua vez, diz respeito ao cidadão do Estado indiano, o qual é composto por uma pluralidade de religiões: hinduísmo ( $80,5 \%$ da população), islamismo $(13,4 \%)$, cristianismo (2,3\%), siquismo (1,9\%), budismo $(0,8 \%)$, jainismo $(0,4 \%)$ e outras religiões $(0,6 \%)$ (Fonte: Census of India. Office of the Registrar General \& Census Comissioner, 2001).

${ }^{3}$ O presidente e o vice-presidente da Hindu Mahasabha, à época da fundação (1915), eram V.D. Savarkar, formulador da concepção original de Hindutva, e K. B. Hedgewar, fundador do Corpo Nacional de Voluntários (RSS).

${ }^{4}$ Deve-se lembrar, ainda, que o nacionalismo hindu constituiu uma reação à entrada de missões cristãs na Índia, a partir de 1813, bem como ao posicionamento ambíguo da administração colonial em relação às instituições religiosas locais. Para uma discussão mais detalhada sobre o tema, ver Oliveira, 2007.

${ }^{5}$ Desde o século 19, o movimento nacionalista indiano foi marcado pela coexistência de correntes de pensamento político divergentes principalmente no que se refere à relação entre religião e poder estatal: nacionalismo hindu, separatismo muçulmano e nacionalismo secular. Para os nacionalistas hindus - defensores da idéia de que as crenças e a história dos hindus, na condição de população majoritária do país, deveriam fornecer a base ideológica para um Estado indiano concebido como um Estado hindu - e separatistas muçulmanos - para os quais a preservação da unidade nacional após a independência dependeria da possibilidade de se estabelecerem relações de igualdade entre duas nações distintas, a hindu e a muçulmana -, a religião seria o fundamento da nacionalidade e da atividade política de modo geral. A terceira corrente, o nacionalismo secular, afirmava que, devido às próprias diferenças entre hindus e muçulmanos, seria necessário dissociar religião e atividade política e reconhecer todos os cidadãos indianos como detentores de direitos iguais como indivíduos e não como membros de uma religião específica (BRASS, 2001; KAVIRAJ, 1997).

${ }^{6}$ Em linhas gerais, à época da independência da Índia, a questão muçulmana - reivindicação de um Estado independente para os muçulmanos - suscitou intensos debates e deliberações em torno de duas alternativas: a criação de um único Estado, no qual prevalecesse a união entre hindus e muçulmanos, ou a criação de dois Estados, um Estado muçulmano e um Estado indiano. A última alternativa prevaleceu e, em 1947, foram criados a Î́ndia e o Paquistão.

${ }^{7}$ Shakha pode ser traduzido como ramo de árvore, o que remete à idéia, segundo os próprios nacionalistas hindus, de que os vários ramos (shakhas) ao redor do mundo formariam uma bela árvore.

${ }^{8}$ Partindo da concepção de que o hinduísmo havia se degenerado e de que necessitava ser revitalizado, Dayanand Saraswati argumentou a favor do retorno aos quatro Vedas, os quais, como revelação literal da palavra 
de Deus, deveriam ser a fonte primeira da autoridade temporal e das práticas hindus. O próprio Dayanand comentou os Vedas, procurando demonstrar que todo o conhecimento científico ocidental já se encontrava em tais textos sagrados. Recorreu, nesse caso, à concepção de uma religião hindu - e, mais especificamente, uma religião védica - racional, universal. Além disso, o reformador social hindu rejeitou o politeísmo e a adoração de imagens, defendendo, em contrapartida, o caráter monoteísta da religião védica. De modo geral, a pretensão de movimentos como a Sociedade Ariana era criar um hinduísmo moderno que pudesse ser respeitado pelo mundo ocidental - uma vez que era monoteísta e baseado em livros sagrados, tal como grande parte das religiões existentes no Ocidente - e que pudesse servir como base moral para a ação (BHATT e MUKTA, 2000; VAN DER VEER, 2001, 2002).

${ }^{9}$ Eremitas ou mendicantes religiosos.

${ }^{10}$ Para uma discussão detalhada da influência do pensamento de líderes religiosos do período de renovação hindu (século 19) sobre o discurso nacionalista hindu contemporâneo, ver Oliveira, 2007.

${ }^{11}$ Foram criadas, ainda, novas categorias de cidadania com vistas a manter/estabelecer vínculos entre os migrantes e o Estado indiano - trata-se dos Overseas Indians, divididos em Non-Resident Indians (NRI) e People of Indian Origin (POI) -, assim como foi instituído um Comitê para a Diáspora Indiana.

12 Para uma discussão sobre a concepção essencialista de identidade nacional, ver Calhoun, 1995, 2001; Woodward, 1997.

${ }^{13}$ Somente após 1833, ano de cessação das atividades comerciais da Companhia na Índia, é que se pode observar a existência de um órgão de gestão colonial atuando em nome da Coroa britânica, a qual assumiria o controle direto da colônia indiana apenas em 1858 (PANIKKAR, 1964, 1977; POUCHEPADASS, 2004; THAPAR, 1969).

${ }^{14}$ Podem-se mencionar, por exemplo: a rota de comércio do Oceano Índico que facilitou a migração de indianos para a costa leste da África, para o Sudeste asiático e para o que hoje se considera o Oriente Médio; os contratos de aprendizagem por meio dos quais, sob condições extremas de exploração, indianos emigraram para Fiji, Sri Lanka, Suriname, Guiana, Ilhas Maurício, Malásia, Trinidad e África do Sul; a emigração de comerciantes para a África Oriental nas primeiras décadas do século XX; o recrutamento de trabalhadores pobres para atuar na reconstrução da Europa (principalmente Reino Unido, Holanda e Alemanha) após a Segunda Guerra Mundial; a emigração de trabalhadores para Oriente Médio e de profissionais especializados para países como EUA, Austrália, Reino Unido e Canadá, nas últimas décadas do século XX (Lal, 1997a, 1997b). 